\title{
Does disease-irrelevant intrathecal synthesis in multiple sclerosis make sense in the light of tertiary lymphoid organs?
}

\author{
Mickael Bonnan* \\ Service de Neurologie, Centre Hospitalier F. Mitterrand, Pau, France
}

\section{Edited by:}

Amy Lovett-Racke, The Ohio State

University, USA

\section{Reviewed by:}

Thomas G. Forsthuber, The University of Texas at San Antonio, USA

Astrid E. Cardona, The University of

Texas at San Antonio, USA

\section{*Correspondence:}

Mickael Bonnan, Service de Neurologie, Centre Hospitalier F.

Mitterrand, 4 Boulevard Hauterive,

Pau 64000, France

e-mail:mickael_bonnan@yahoo.fr
Although partly disease-irrelevant, intrathecal immunoglobulins (Ig) synthesis is a typical feature of multiple sclerosis (MS) and is driven by the tertiary lymphoid organs (TLO). A long-known hallmark of this non-specific intrathecal synthesis is the MRZ pattern, an intrathecal synthesis of Ig against measles, rubella, and zoster viruses. This non-specific intrathecal synthesis could also be directed against a wide range of pathogens. However, it is highly problematic since brain TLO should not be able to drive the clonal expansion of lymphocytes against alien antigens that are thought to be absent in MS brain. We propose to explain the paradox of non-specific intrathecal synthesis by discussing the natural properties of TLO. In fact, besides local antigen-driven clonal expansion, circulating plasmablasts and plasma cells (PC) are non-specifically recruited from blood and gain access to survival niches in the inflammatory CNS. This mechanism, which has been described in other inflammatory disorders, takes place in the TLO. As a consequence, PCs recruited in brain mirror the individual's history of immunization and intrathecal synthesis of $\operatorname{lgG}$ in MS may target a broad range of common infectious agents, a hypothesis in line with epidemiological data. Moreover, the immunization schedule and its timing may interfere with PC recruitment. If this hypothesis is correct, the reaction against EBV appears paradoxical: although early infection of MS patients is systematic, intrathecal synthesis is far lower than expected, suggesting a crucial interaction between MS onset and timing of EBV infection. A growing body of evidence suggests that the non-specific intrathecal synthesis observed in MS is also common in many chronic CNS inflammatory disorders. Assuming that cortical TLO in MS are associated with typical sub-pial lesions, we have coined the concept of "TLO-pathy" to describe these lesions and take examples of them from non-MS disorders. Lastly, we propose that intrathecal synthesis could be considered a strong hallmark of CNS TLO and might be used to monitor future TLO-targeted therapies.

Keywords: multiple sclerosis, lymphoid tissue, antibody response, cerebrospinal fluid, Epstein-Barr virus

\section{INTRODUCTION}

The intrathecal synthesis of immunoglobulins (Ig) and oligoclonal bands $(\mathrm{OCB})$ is an early occurring event in the course of multiple sclerosis (MS), and once acquired, persists essentially unchanged throughout life, whatever therapies are undertaken [see review in Ref. (1)]. As a consequence, intrathecal Ig secretion is still a major supportive diagnostic argument. However, the antigens targeted by these intrathecal Ig are often considered to be largely unknown and studies have yielded contradictory results (2). The lack of specificity against the three major myelin proteins does not preclude any other specificity (3), either against other minor myelin proteins or brain antigens, or against foreign antigens (viral antigens for example). Indeed, the failure to find a major antigen for an intrathecally synthesized Ig may not relate to a nonsense antibody production but instead may reflect the molecular complexity of the CNS and the presumed antigenic target. Studies without any a priori, which are better suited to revealing unknown specificities, have confirmed the existence of an immense pool of targets against other brain membrane proteins, lipids, and glycolipids [see Ref. (3)]. Paradoxically and despite these huge efforts, the puzzling problem of non-brain targets directed against a virus in the absence of brain infection seems irreconcilably contradictory with an intrathecal antigen-antibody selection. Although the concept of molecular mimicry has long been debated [review in Ref. (4)], epidemiological data suggest that mimicry alone cannot explain the intrathecal synthesis that occurs against so many infectious agents $[(5,6)$, see below]. Here, we reassess the pathophysiological consequences of this non-specific (disease-irrelevant) intrathecal reaction in MS in the light of the most recent immunological data and develop a new concept with great explanatory potential by bringing together the apparently contradictory data in the literature.

First, we comprehensively review the non-specific intrathecal reaction in MS. While the classical "MRZ pattern" is the hallmark of this non-specific reaction, we argue that MRZ is simply part of a broader non-specific reaction involving many non-brain targets, such as most of the common infectious agents. 
We then explore the conditions necessary to produce and maintain an intrathecal reaction. We first use the example of peripheral (non-brain) lymphoid organ physiology to demonstrate how a sustained antibody secretion may take place in a given lymphoid organ, even if the mature B-cells originate from a different immune compartment. We posit that disease-irrelevant Ig secretion is a common feature of tertiary lymphoid organs (TLO) in various inflammatory disorders. We then link these observations to the fact that intrathecal synthesis needs the presence of cortical TLO, implying in turn a non-specific intrathecal synthesis.

We then explain why virtually all the CNS disorders associated with intrathecal synthesis may also harbor some non-specific synthesis, and provide evidence for this reaction and its extent in multiple CNS inflammatory disorders. Since intrathecal synthesis involves CNS TLO and bearing in mind that TLO in progressive MS are associated with sub-pial lesions (7), we propose the pathological concept of "TLO-pathy" and provide examples from chronic CNS infections.

Finally, we return to the issue of MS. Since non-specific intrathecal synthesis is directed against many infectious agents, the question arises as to whether an immunization schedule could be used to accurately assess the time of MS onset? Secondly, although EBV infection precedes MS in virtually all patients, the intrathecal reaction against EBV is paradoxically very low. This might either illustrate the role of the immunization schedule or a specific relationship between EBV and MS.

In practice, intrathecal synthesis in MS informs the clinician mostly of the persistence of CNS TLO at the pathological level. Such information obtained from a simple lumbar puncture could help in the monitoring of future treatments targeting CNS TLO.

\section{THE CONCEPT OF NON-SPECIFIC INTRATHECAL SYNTHESIS IN MS \\ THE "MRZ" PATTERN - A TYPICAL NON-SPECIFIC INTRATHECAL RESPONSE}

Barring a still unknown cross-reactivity from viral particles and the brain, the "MRZ" reaction, which is the intrathecal synthesis of Ig against measles, rubella, and varicella-zoster virus, has long been considered to be highly specific of MS, but does not target the brain (8). The IgG fraction that belongs to this specific response in the CSF is estimated to represent $<2 \%$ of the total amount of CSF IgG (8-10) and only a minor fraction of total OCB (11-13), but it is one that has a major diagnostic specificity. Moreover, the MRZ reaction is observed in MS patients although none have been reported to have intrathecal production of these viruses or to suffer from encephalitis involving any of these viruses. The proportion of MS patients having an elevated antibody index (AI) against $\geq 1$ of these viruses is $89 \%$ (8), and increases over time and MS evolution. About one-third of patients also react against Herpes virus $(\mathrm{MRZH})$. The MRZ reaction, which is sometimes present in the absence of $\mathrm{OCB}$, is more frequent in clinically isolated syndromes (CIS) who will soon convert (14) and its proportion increases in OCB-negative patients during follow-up (15). In a retrospective study of MRZH in OCB-negative patients, 4 (18\%) of 22 patients having been diagnosed with MS within the last 5 years had at least one elevated AI, compared to $17 / 28(61 \%)$ in those with a longer disease duration (15).

Intrathecal synthesis is poly specific in about a quarter of MS patients: one elevated AI (against M, R, Z, or H) in 22\%, two AI in $17 \%$, three $\mathrm{AI}$ in $4 \%$, and four $\mathrm{AI}$ in $2 \%$ (15). The number of elevated AI strongly correlated both with age at spinal tap and disease duration (15). Immunosuppressive treatments (mitoxantrone and azathioprine) seem ineffective to prevent persistence of the MRZ pattern (16). Titers of AI against MRZ correlated with the T2 load in MRI, significantly for measles AI and with a trend for rubella and zoster AI (17). However, this correlation is limited to the early phase of the disease since intrathecal Ig secretion is rather stable over time, although white matter T2 load increases (17), but no data is available to correlate with gray matter lesions. Unlike in controls, no decline in AI levels occurs with age in MS patients either considering serum or CSF titers, and there is even a slight increase $(18,19)$. Moreover, there is a trend to a higher proportion of elevated AI in SP-MS than in RR-MS patients (20).

\section{BROADENING THE MRZ PATTERN TO MULTIPLE INFECTIONS}

Beyond the MRZ pattern, high intrathecal synthesis against many other infectious agents has been reported in MS: rotavirus (21); toxoplasmosis in $10 \%(8,10)$; herpes in one-third of cases $(8$, 21); Chlamydia pneumonia in 20-82\% (9, 11, 20, 22-25); HHV6 in $20-30 \%(26,27)$; Borrelia burgdorferi in 26\% (28); mumps (29); influenza B (29); rotavirus (29); adenovirus (30); and vaccinia $(30,31)$. In each study, seroprevalence for infection was the same in both MS and controls, whereas controls had no specific intrathecal reaction. Unfortunately, some of these older studies used heterogeneous methodologies and some of them should be validated with recent stringent criteria (10). The same gradient of frequency from RR-MS to SP-MS is observed with intrathecal productions against many infectious agents $(20,22)$. This polyspecific intrathecal IgG response in MS mirrors the individual's history of previous infections and immunization and depends on the local prevalence of each disorder. For example, a lower proportion of rubella-AI is observed in MS patients from Cuba than those from Germany, in line with a lower incidence of rubella infection (6). Interestingly, the sex-ratio is far lower $(\mathrm{M}: \mathrm{F}=1: 6)$ than expected $(\mathrm{M}: \mathrm{F}=1: 1.9)$ in Cuban patients synthesizing intrathecal rubella antibodies, a finding reliably explained by immunization campaigns directed toward females (but not males) in a context where natural infection is very low (6). In Czech patients, a high proportion of AI against $B$. burgdorferi has been observed (up to 26\%) (28). In fact, the rate of intrathecal reaction against a given germ correlates with the rate of seroprevalence, very highly seroprevalent infections (about $90 \%$ for measles and rubella) having the higher rate of intrathecal reactivity whereas low prevalence of HSV is associated with scarce reaction (29). This former epidemiological subjection and the broad range of infectious agents potentially involved plead against a trivial cross-reactivity of intrathecal synthesis with brain antigens. We hypothesize that a high level of intrathecal reaction against all the common antigens (infectious/vaccinal or not) is probably common in MS and could throw light on the pathophysiology of MS. 


\section{KEY PROPERTIES OF CNS TERTIARY LYMPHOID ORGANS EXPLAIN INTRATHECAL SYNTHESIS, INCLUDING NON-SPECIFIC SECRETION}

PLASMA CELLS MAY LOCATE NOT ONLY IN BONE MARROW BUT ALSO WIDELY THROUGHOUT THE PERIPHERAL LYMPHOID ORGANS

The protracted presence of intrathecally secreted IgG against infectious agents sparing brain supposes the non-specific recruitment and survival in the intrathecal compartment of long-lived plasmocytes originating from a different immune compartment, where the B-cell response against infectious agents previously took place. The ability to develop an immune response in a compartment and to transfer specific B-cells to another unexposed compartment is a common immunological feature outside of the brain $(32,33)$.

During immune activation in the periphery, naive $B$ lymphocytes encountering antigens are committed to plasmablasts and undergo hypermutation in germinal centers of secondary lymphoid organs. Then, specific plasmablasts appear in the blood for a few days on their way to the survival niches, where they differentiate into plasma cells (PC) (32) (Figure 1). Most of the niches are situated in bone marrow (a primary lymphoid organ) (34). Since the frequency of PC in bone marrow is constant throughout life (about $0.5 \%$ ), newly formed plasmablasts migrating to bone marrow compete with PC already occupying survival niches (34). Thus a majority of newly formed plasmablasts arriving in the bone marrow fail to locate to an appropriate niche (32). This competition for a limited number of survival niches may play a key role in the regulation of serum antibody levels and has also been demonstrated in different animal species (34). However, niches are also available in peripheral secondary and TLO where they display the ability to retain the newly formed PC (32, 35-39). The retention frequency of $\mathrm{PC}$ for a given specificity strongly depends on the lymphoid organ: for example, PC against tetanus toxin preferentially reside in secondary lymphoid organs such as tonsils, and their antibody titers stem from this compartment (35). It also depends on the route of immunization, making specific B-cells more numerous in the draining lymph nodes although they are present to a lesser extent throughout the lymphoid system: for example, a massive rectal immune response is obtained after rectal immunization, yet a rectal response, although minor, is also obtained after gastric or systemic immunization (33). The frequency of disease-irrelevant PC in TLO does not depend on the underlying disorder: for example, the same anti-tetanus toxin IgG concentration is obtained in the culture of synovial extracts (containing TLO) from osteoarthritis or rheumatoid arthritis (38) as in chronic graft rejection (37). It thus appears that non-specific Ig secretion is a natural condition of peripheral TLO.

\section{ARE ANTIBODY-SECRETING CELLS HOSTED IN TLO SURVIVAL NICHES, THUS EXPLAINING THE MRZ PATTERN BY NON-SPECIFIC NICHES OFFERED BY CNS INFLAMMATORY LESIONS?}

Depending on the primary antigenic stimulation, the estimated half-life of long-lived PC varies from 11 years (tetanus) to more than 100 years (measles, mumps), but long-lived PC expelled from niches during competitive process undergo apoptosis (39). In fact, prolonged survival necessitates an anti-apoptotic environment provided in the survival niches by multiple factors (multicomponent PC niche) [review in Ref. $(32,39)$ ]. Although the complex factors conditioning recruitment, differentiation and survival of $\mathrm{PC}$ in niches are still incompletely deciphered and vary depending on the different immune compartments (32), CXCL12 expression by stromal cells and vasculature is the major determinant to retain blood plasmablasts in bone marrow $(32,34)$. In MS, CXCL12 is elevated in CSF, secreted by astrocytes (40), and expressed in the endothelial lumen of lesions in the vicinity of lymphoid infiltrates (41) where PC infiltrates are usual, suggesting that MS brain is ideally equipped to retain non-specific circulating plasmablasts. Although no data is available for meningeal lesions, one could also expect a meningeal CXCL12 expression similar to that in deep lesions (41). The presence of PC inside white matter lesions and meninges in MS has already been described $(42,43)$. According to the previous hypothesis, peripherally activated plasmablasts specific to infectious agents may egress from blood owing to CSF attractant chemokines secreted in brain lesions (i.e., CXCL12), reach survival niches in the CSF and brain, differentiate to PC without any antigen (re)challenging, and finally secrete non-specific intrathecal IgG over a long period (Figure 2). Another mode of interaction of PC in survival niches may involve T-cells, since PC depletion in lymphoid organs following alemtuzumab treatment may be associated with the loss of other cells supporting PC survival (36). Although these data were obtained in experimental

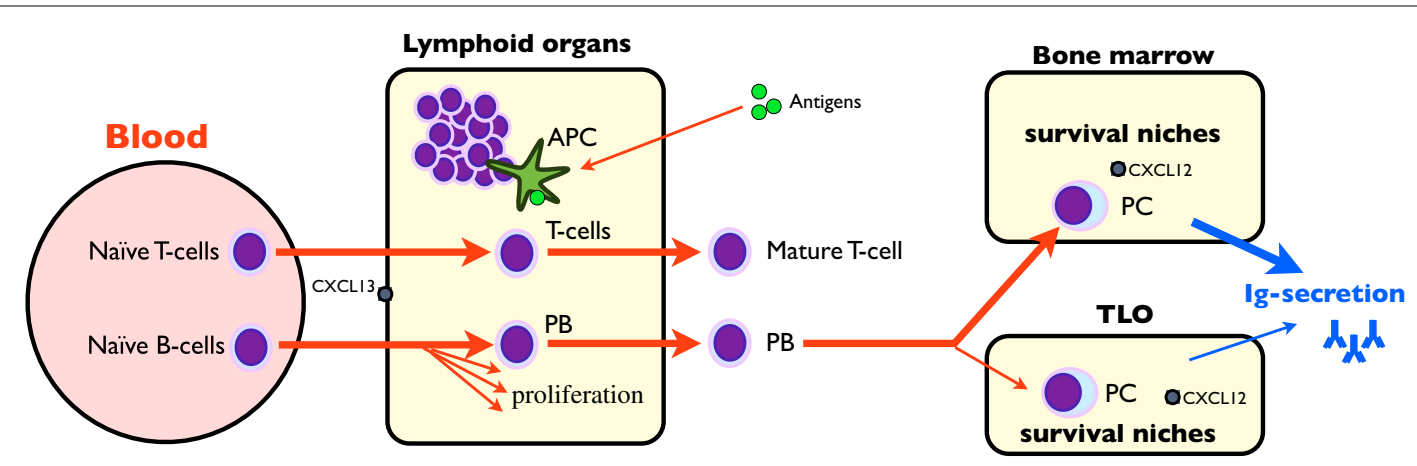

FIGURE 1 | Schematic Ig synthesis pathway. Naïve B-cells are classically recruited in lymphoid organs where they undergo somatic hypermutation, proliferate, and recirculate as short-lived plasmablasts (PB). PB migrate to bone marrow, differentiate to long-lived plasma cells (PC), and synthesize the bulk of plasmatic lgG. However, secondary/tertiary lymphoid organs may also retain $\mathrm{PC}$ in survival niches, where they participate in IgG synthesis. 


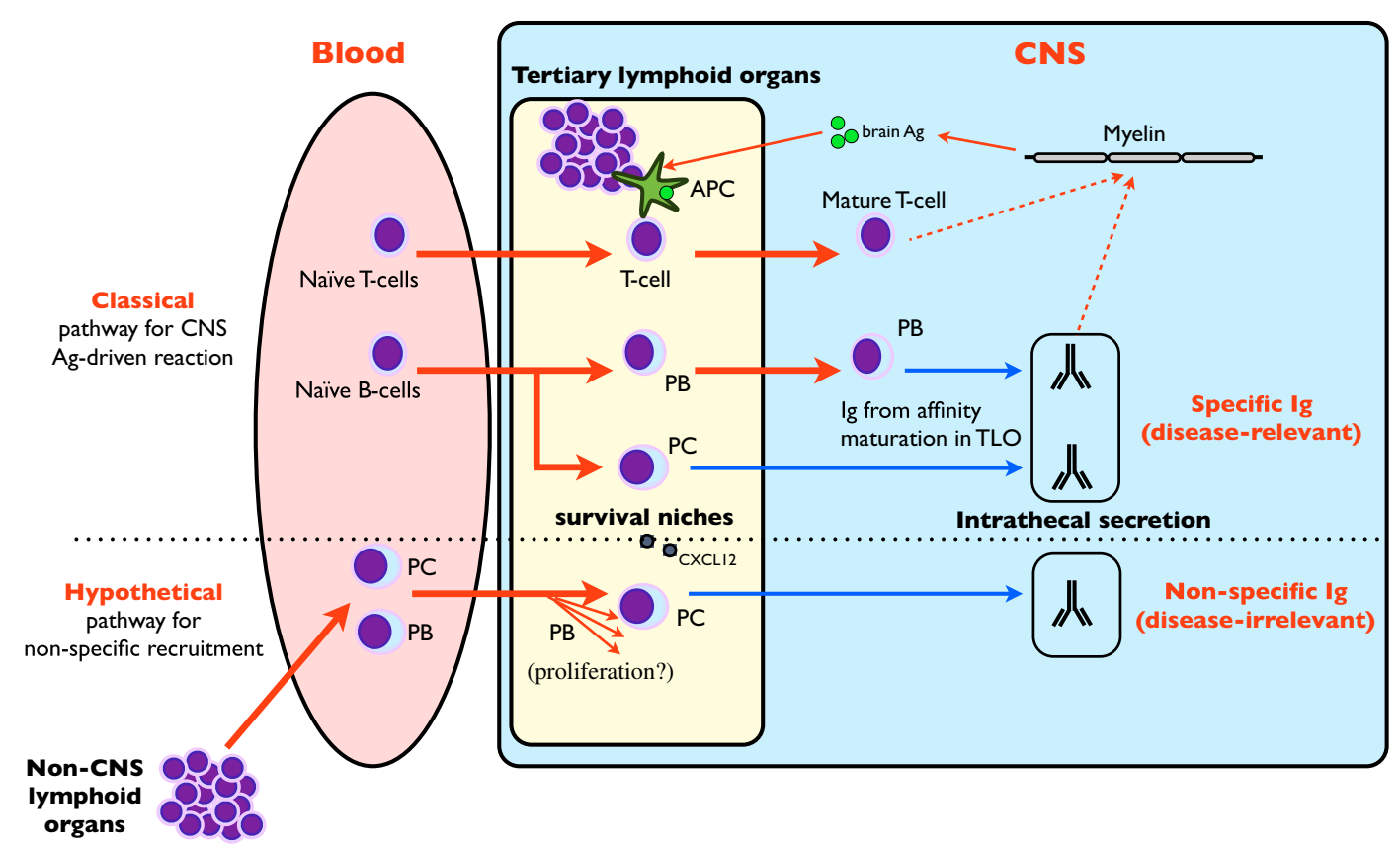

FIGURE 2 | Role of tertiary lymphoid organs in intrathecal synthesis. CNS TLO are able to mount a classical antigen-driven T and B-cell clonal response that is responsible for intrathecal synthesis against brain-borne (and possibly disease-relevant) antigens (1, 46-48) (upper part of figure). A hypothetical pathway (lower part of figure) may involve the non-specific recruitment of circulating plasmablasts $(\mathrm{PB})$ and plasma cells (PC) from blood by CNS TLO. These disease-irrelevant PB may further differentiate after proliferation to $\mathrm{PC}$, home in on survival niches provided by TLO and maintain the non-specific intrathecal Ig synthesis. settings unrelated to MS, they offer an attractive explanation of the (slight) repression of intrathecal synthesis observed for the first time in MS patients treated with natalizumab $(44,45)$.

Similar to MS, the extreme versatility of disease-relevant antibodies and the presence of disease-irrelevant antibodies like antitetanus toxin have been directly associated with TLO function [chronic graft rejection (37), rheumatoid arthritis (38)]. We suggest that the intrathecal production of disease-irrelevant antibodies may be due to antibody-secreting cells harvested in survival niches of TLO, as in numerous other peripheral disorders (37, 38). Definitive proof - but hard to obtain - would be obtained by using in vitro cultures of explanted MS TLO and assaying disease-irrelevant antibodies in the supernatant. Moreover, since most experiments to date concerning Ig secretion in body compartments have been done with anti-tetanus toxin, it would be interesting to evaluate AI anti-tetanus toxin in MS patients, in whom high levels could be expected to occur frequently.

Under these assumptions, a protracted polyspecific Ig response would indicate an enhanced pre-existing B-cell promoting environment. The MRZH pattern mainly mirrors the commonest infections, i.e., those that are the most likely to select abundant specific plasmocytes, which are subsequently recruited nonspecifically by the brain TLO. Moreover, intrathecal antibodysecreting cells recruitment should be progressive and achievement of a full MRZ pattern may take years or even decades. This is in fact observed in clinical studies where mean age at spinal tap and disease duration correlate with the number of elevated antibody indices (15). Half of the patients having fewer than 5 years of disease duration have no elevated AI (MRZ), whereas $70 \%$ of those with more than 10 years duration have $A I \geq 2$ (15). It would be of particular theoretical interest to confirm the MRZ pattern in MS patient populations where OCB prevalence is lower, in association with HLA DRB1*04 (15).

The presence of a polyspecific intrathecal synthesis as soon as the index event occurs suggests that an enhanced B-cell-promoting environment exists before or at the time of the first event, and gives a high probability of a chronic inflammatory process already underway at the moment of the first clinical symptom (6). This raises two further issues: (1) a polyspecific intrathecal response might also be associated in non-MS patients susceptible to CNS TLO (e.g., in chronic CNS infections); (2) the schedule of peripheral non-specific infections (e.g., MRZH infections) might interfere with the ancientness of the TLO-leading disease (i.e., MS or brain infection) in the risk of developing a bystander non-specific intrathecal synthesis.

\section{NON-SPECIFIC SYNTHESIS IS ALSO A FEATURE OF NON-MS CNS DISORDERS HARBORING INTRATHECAL SYNTHESIS NON-SPECIFIC VS. INFECTION-RELATED INTRATHECAL ANTIBODY SYNTHESIS}

The fraction of a specific antibody response against an infectious agent within the complete intrathecal IgG response is called the Specific Fraction $\left(F_{\mathrm{s}}\right)(49)$. For example, the calculation of an $F_{\mathrm{s}}$ value for measles at $2 \%$ means that $2 \%$ of the total intrathecal IgG response is directed against measles. Neuro-infections are expected to be associated with very high $F_{\mathrm{s}}$ against the virus: $F_{\mathrm{s}}$ are 8.8\% (3.5-12.5\%) for HSV in HSV encephalitis (HSVE), $18.8 \%$ $(11.8-27.5 \%)$ for measles in subacute sclerosis panencephalitis 


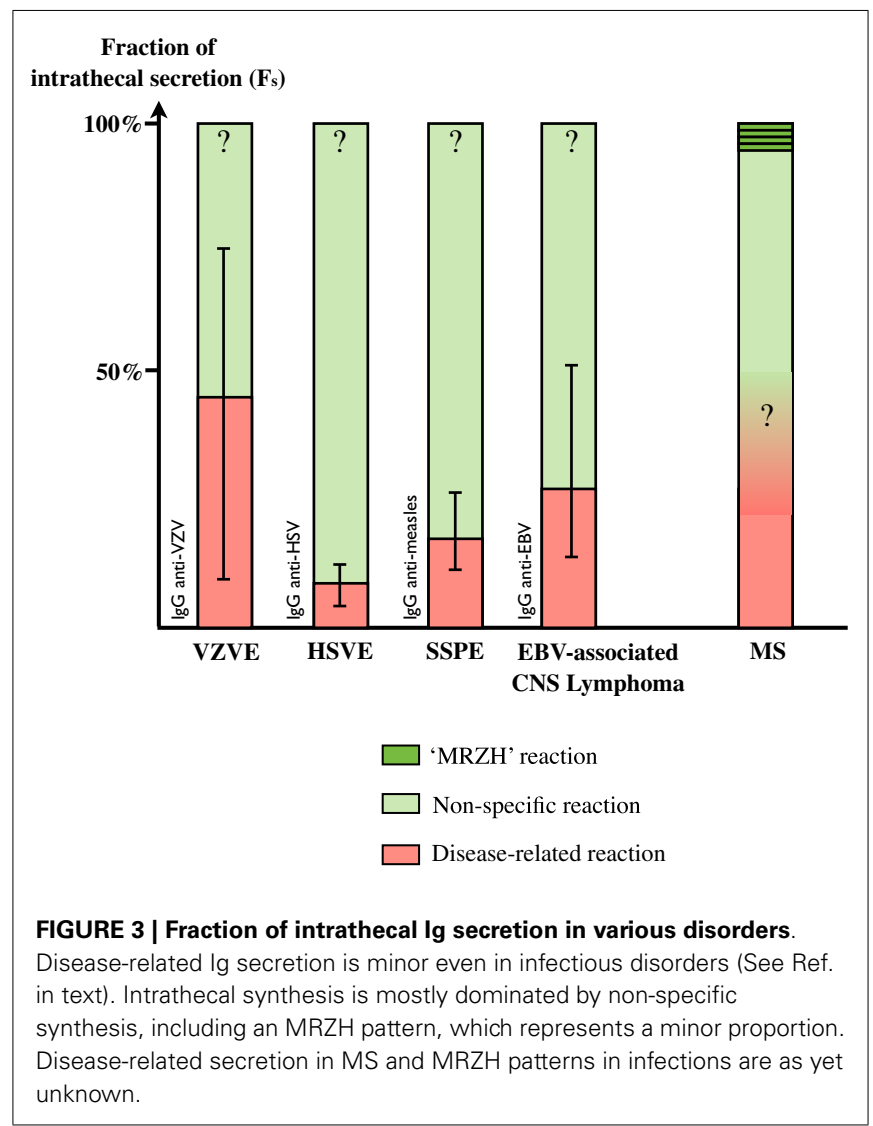

(SSPE) $(49,50)$ and 45\% (13-73\%) for VZV encephalitis (51). Unfortunately $F_{\mathrm{S}}$ values for relevant infectious agents are not available in other infectious settings such as neuro-syphilis and neuro-borreliosis. In EBV-associated post-transplantation brain lymphoma, median $F_{\text {s }}$ anti-EBV is $27.8 \%$ (14-53.6\%) (52).

In MS, each specificity in the MRZH reaction typically retains a very low median $F_{\mathrm{S}}$ of $0.2-1.3 \%$ (ranging from 0.03 to 5.3 ) $(49,51,52)$ and comparable results are obtained for $F_{\mathrm{s}}$ anti-EBV (52). These specific $F_{\mathrm{s}}$ results in neuro-infections are about 40 -fold higher than those found in MS patients without overlap. Interestingly, in two cases of HSVE, median $F_{\mathrm{s}}$ anti-VZV were $0.3-4.9 \%$, in the same range as those of MS patients (51). In other words, about $80 \%$ of the intrathecal $\mathrm{Ig}$ in infectious pathologies are directed against non-causative antigens $(10,49,50)$, i.e., a non-specific intrathecal synthesis is very common even in neuro-infections (Figure 3).

The specific antibody fraction of the total IgG in blood $\left(R_{\mathrm{S}}\right)$ corresponds to the intrathecal fraction of antibodies in $\operatorname{CSF}\left(F_{\mathrm{S}}\right)(49)$. For example an $R_{\mathrm{s}}$ value for IgG against measles of $0.1 \%$ means that a $0.1 \%$ of the total IgG pool is directed against measles. Median $R_{\mathrm{s}}$ values range from 0.06 to $0.19 \%(0.01-1.4 \%)$, which is a very low fraction of total blood IgG and does not differ between MS patients and controls (8). The median ratio $F_{\mathrm{s}}: R_{\mathrm{s}}$ for MRZ is 3-3.5 with a wide range extending from 0 to $47.4(10,49)$, confirming a more intense intrathecal synthesis of specific antibodies.

The variability in the amount of specific intrathecal synthesis between neurological infections and MS patients as compared to blood deserves discussion. The amount of intrathecally secreted specific antibodies should be proportional to the number of intrathecal PC. If we consider that circulating PC are nonspecifically and randomly selected from blood to home to CNS TLO, the relative proportion of each specific IgG synthesis in CSF should grossly parallel their proportion in blood. For example, if IgG secretion in blood against viruses V1 and V2 is 0.5 and $1 \%$ of the total blood $\operatorname{IgG}$, one could expect the same proportion and the same ranking of IgG secretion against those viruses in CSF. Yet this is not the case. The ranking of specific antibodies concentrations in blood and CSF differs in 67\% of MS patients, confirming that CSF IgG secretion does not simply mirror blood secretion. Intrathecal synthesis of the specific antibodies occurs independently from each other (49). We propose two nonmutually exclusive explanations. A first hypothesis involves the differential intrathecal proliferation of specific B-cells after being recruited from blood but before being committed to terminal differentiation into PC, owing to a favorable intrathecal lymphoid environment. Unfortunately, no data is available about the clonality of the IgG involved in the MRZ response. A second hypothesis posits a non-random brain homing of circulating plasmablasts. It seems unlikely that plasmablast homing is driven by IgG specificity. Rather, the critical intensity of plasmablast/PC recruitment to brain owing to the intensity of the peripheral immune response to infection could be involved. For example, since immunity is now largely obtained by vaccination, which has been used for almost 30 years, rather than by infection; has intrathecal synthesis against measles changed over time? A study suggests that patients with a history of measles infection are more prone to have detectable anti-measles antibodies in the CSF ( 89 vs. 67\%) and at higher levels than those who have been vaccinated (19). Unfortunately, rates of CSF anti-measles secretion were not correlated to age at infection and an exact determination of intrathecal synthesis was lacking, so further studies on this theme are required.

\section{POLYSPECIFIC INTRATHECAL SYNTHESIS IN NON-MS DISORDERS}

The polyspecificity of the intrathecal response is not restricted to MS but is also common in response to infections [see above (49)] or non-MS CNS inflammation.

(a) Autoimmune disorders. In large control groups of nonautoimmune and autoimmune non-MS neurological disorders, a monospecific MRZH response was present in respectively $3 / 37(8 \%)$ and $3 / 16(19 \%)$ while multiple responses were never observed $(15,25,28)$. In one series, $1 / 1$ Sjögren and 1/1 Wegener and 3/9 lupus had an MRZH response (including two with intrathecal synthesis of anti-DNA) (53). In a series of 17 primary Sjögren's syndrome, 11 had OCB, 6 had a high IgG index, 13 had a high IgM index, 8 had at least a reaction (immunoblot) against one specificity of the MRZH pattern, but none had anti-MBP (54). Interestingly, many series harbor a frequency of abnormal specific AI at low frequency in non-MS disorders but at intermediate frequency in the autoimmune non-MS disorders group $(22,28)$. When focusing upon paraneoplastic neurological syndromes (characterized by anti-Hu, -Yo, -Ri, -Ma, -Ta or -Tr antibodies either 
in serum or CSF, and by a CNS acute inflammation), a monospecific MRZ response was present in 7/34 vs. 0/42 in MS, whereas a bispecific or a trispecific response was obtained in none (0/34) of these syndromes vs. $37 / 42$ MS patients (55). A bispecific response was obtained in $1 / 20$ neuromyelitisoptica (NMO) (16). No intrathecal synthesis was observed against CMV or EBV in a large group of amyotrophic lateral sclerosis (ALS) and chronic inflammatory demyelinating polyneuropathy (CIDP), a setting in which intrathecal synthesis is usually absent (56). In CNS lymphoma, AI is commonly elevated for EBV but not against measles, yet results obtained with EBV may obscure the interpretation due to its dedicated role in lymphoma's pathophysiology (52).

(b) Infectious disorders. In a few cases of neuro-borreliosis, neuro-syphilis, or neurotuberculosis, a MRZ synthesis occurs against one species in a few percent and below $0.1 \%$ for $M+R+Z(8,57,58)$. However, neuro-syphilis should be studied differently. There has been one case of neuro-syphilis showing elevated AI for MRZ and mumps (59). In HIV infection, apart from elevated AI against HIV itself and HSV, C. pneumoniae-specific OCB are found in $3 / 5$ patients, HSV OCB in half of all patients, as well as OCB against CMV and toxoplasma $(25,58,60)$. In a series of 17 HTLV-1, only one showed a complete MRZ response (57), but none did in a series of 11 HSVE (61). In another series of nine HSVE, all had a persistent response against VZV and one had an intrathecal synthesis against measles (62). In the latter patient, synthesis against measles was absent at week 1 , appeared at week 4 , and persisted at year 4.5 (62). In a series of seven children having suffered from HSVE when they were younger, $3 / 5$ who underwent lumbar puncture more than 8 years later had a partial or complete MRZ pattern but none did of those who underwent lumbar puncture in the same year (63). Moreover, IgG index increased over time, reaching a maximum at $1-2$ months, then mostly remained elevated years later $(63,64)$. Systematic studies are lacking but in a single case of HSVE, an initially high AI for herpes subsequently abated whereas AI against multiple viruses (measles, parainfluenza, influenza, and adeno) increased (63). A systematic study of 10 mumps meningitis revealed a combination of multiple intrathecal reactivity against measles, herpes, adenovirus, or rubella in most patients, in the same range as that observed in MS patients (65). In one case, non-specific reactivity against measles and herpes was already present at day 1 whereas mumps reactivity appeared at day 10 (65). In acute neuro-borreliosis, the presence of an MRZ pattern is documented in up to $7 \%$ of patients, whereas in late neuro-borreliosis, a considerable number of OCB were not attributable to B. burgdorferi (66), and an MRZH pattern with three specificities was observed (58).

(c) Genetic disorders. The systematic study of CNS genetic disorders may open up an unexpected window of reciprocal intrathecal autoimmunity. A seminal work in Batten's disease, which is a purely degenerative CNS genetic disorder, demonstrated a high level of intrathecal antibodies against GAD (glutamic acid decarboxylase) in patients and in the murine model (67). Results are even more interesting in Xlinked adreno-leukodystrophy (ALD). OCB was found in only one patient in 13 with typical ALD but was absent in asymptomatic patients (68). However intrathecal synthesis was present in all but 1 of the 14 ALD patients and in none of the 12 asymptomatic patients (68). This synthesis predominates in IgA in all cases but one, but only rarely in IgG or IgM. Interestingly, intrathecal synthesis was found negative in CSF sampled before the onset of brain symptoms and later became positive. The MRZ pattern was absent in all cases, but none had a follow-up exceeding 2 years after onset of brain symptoms (68). Moreover, the inflammatory component in ALD is a secondary event, mostly localized in the center of lesions but sparing the edges, contrary to MS (68). The two latter examples suggest that whatever the chronic brain lesion, an intrathecal non-specific inflammation may be triggered.

In conclusion, there is a lack of large systematic studies of MRZH (and other specificities), AI in chronic protracted autoimmune brain disorders and especially in chronic brain infections, taking into account age at infection onset, immunizations prior to and during the infections and duration of disease. However, the above-mentioned data strongly suggest that a polyspecific intrathecal synthesis occurs more commonly than thought in association with long-standing infection/post-infection intrathecal specific response. In line with the progressive enrichment of the MRZ pattern over time in MS, these observations support our main hypothesis postulating a (slowly) progressive recruitment of non-specific PC over time.

\section{COULD WE USE CHRONIC NEUROLOGICAL INFECTIONS AS A MODEL FOR THE STUDY OF NON-SPECIFIC INTRATHECAL IMMUNE SYNTHESIS?}

The above-mentioned arguments support the existence of a nonspecific intrathecal reaction associated with neurological infections. Moreover, this non-specific reaction takes years to develop, since it is more frequent in chronic infections and in older MS patients. The factor triggering MS and the reason why intrathecal inflammation fails to clear in MS are still unknown. From a theoretical point of view, the study of these chronic neurological infections may open up a major opportunity that is unavailable in MS investigations by controlling two key points: infection triggers a specific (and non-specific) intrathecal inflammation and antibiotics cure the cause. This may allow the study of the natural clearance of CNS inflammation after the end of the cause, which may provide information about the late progressive stages of MS.

Nevertheless, from a technical point of view, it now seems very difficult to document non-specific intrathecal synthesis in chronic neurological infections. Thanks to medicine and hygiene, most of the above-mentioned chronic infections (SSPE, HTLV-1, neurosyphilis, chronic neuro-borreliosis) have now practically disappeared from westernized countries. Other chronic protracted CNS infections such as HTLV-1, neurocysticercosis, and trypanosoma, which are associated with a strong specific intrathecal synthesis, are all neglected diseases from tropical areas, and medical research into them and their treatments have been sidelined. HIV infection would lend itself to the long-term study of the progressive enrichment of intrathecal synthesis, but immune dysfunction might interfere during follow-up. 


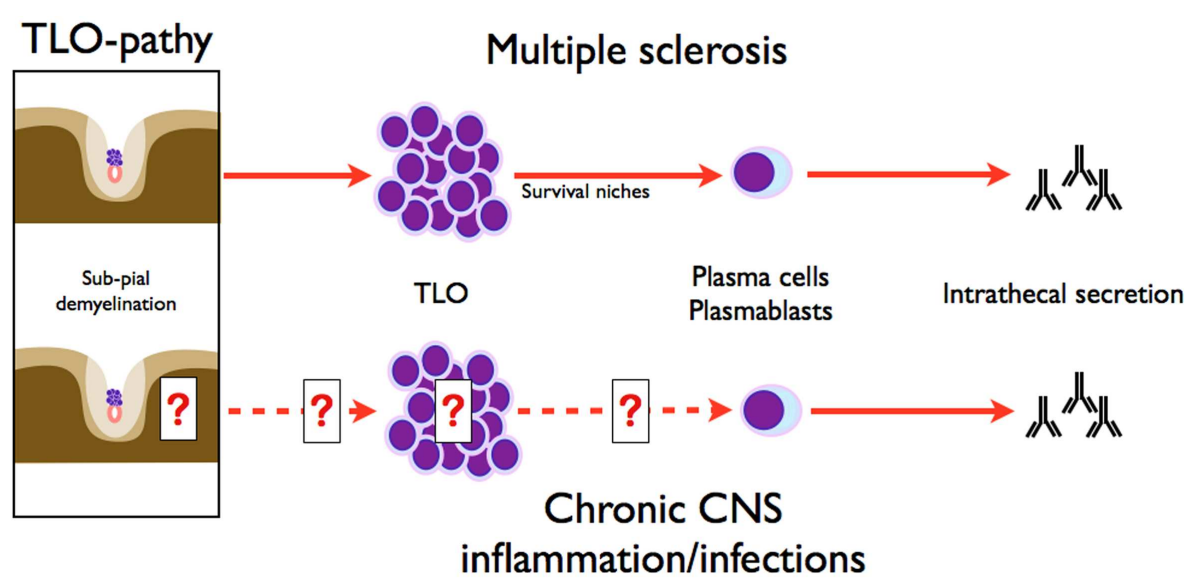

FIGURE 4 | Symmetry of intrathecal synthesis paradigms in MS and chronic CNS inflammation/infections. Intrathecal synthesis in CNS infection implies plasma cells, and as demonstrated herein, needs survival niches supported by TLO. Sub-pial demyelination is associated with TLO, as classically known in MS, but also in chronic CNS inflammation and infections. Therefore, sub-pial demyelination induced by TLO is not a hallmark of MS and defines the concept of TLO-pathy.

\section{RETHINKING SUB-PIAL LESIONS OF PROGRESSIVE MS IN THE LIGHT OF NON-SPECIFIC INTRATHECAL INFLAMMATION: INTRODUCING THE CONCEPT OF "TLO-PATHY"}

Studying intrathecal synthesis in non-MS disorders could be far from futile. Although proof of CNS TLO is lacking in many disorders associated with intrathecal synthesis, owing more to the recentness of the discovery of TLO than to negative studies, no alternative theory better explains the long-lasting intrathecal synthesis observed years after neuro-infection healing, for example after neuro-syphilis, borreliosis, or HSV (Figure 4) (62, 66, 69). Do cortical TLO exist in chronic infections and are they associated with congruent sub-pial lesions as in progressive MS? In a series of nine patients suffering from different types of neuroinfections, two were proved to have meningeal B-cell aggregates (one tuberculous meningoencephalitis, one syphilitic meningitis) (7). Furthermore, sub-pial demyelination (layer I) was observed in syphilitic meningitis (7). In the event of independent study replication, sub-pial lesions associated with cortical TLO should no longer be considered as typical of progressive MS, but should rather be seen (at least in some cases) as bystander lesions induced by TLO independently of the causal disorder: infection, inflammations, or MS (1). Pathophysiology may involve by-products of TLO function like cytokines ( TNF $\alpha$, IFN $\gamma$, etc.), which were shown in vitro to have a noxious effect on cultured brain cells owing to antibody-independent toxicity $(45,70,71)$. As a consequence, sub-pial lesions may be considered as typical of cortical TLO, thus defining a "TLO-pathy," thereby adding a major conceptual brick to the understanding of CNS pathology. We acknowledge that these lesions have been reported only once, but one should remember how long it took to identify these key lesions in MS and that they were never explicitly tracked in other pathological settings. Acknowledging also that CNS pathologies involving intrathecal inflammation are either exceptional (like tropical infections) or too severe to be followed up for decades, MS is nowadays by far the most common cause of chronic intrathecal inflammation.
We suspect that this epidemiological fact has biased observation by associating chronic intrathecal inflammation with MS, not because the association is specific but simply because it is statistically more likely. From a theoretical point of view, it could be important to longitudinally monitor non-MS patients with chronic intrathecal inflammation (implying TLO presence) in order to assess the possible development of progressive sub-pial lesions and brain atrophy reminiscent of the MS progressive phase. This would provide proof of TLO-pathy as a valuable new therapeutic target in all disorders involving intrathecal inflammation, including the still intractable progressive phase of MS.

\section{CAN NON-SPECIFIC INTRATHECAL SYNTHESIS SHED LIGHT ON TIME OF MS ONSET?}

\section{INFLUENCE OF IMMUNIZATION SCHEDULE}

Uncertainty remains about the timing of MS onset in the chronology of infantile MRZ infections or vaccination in the case of rubella, measles, and mumps. Moreover, most studies are dedicated to potentially neuro-infectious agents (measles, rubella, VZV, HSV, EBV, chlamydia), which obscure the analysis since one cannot exclude past subtle CNS infections. What would the results be for common infectious agents devoid of neurotropic effect (i.e., human papillomavirus, anti-tetanus toxin vaccine)? One might regret that anti-tetanus toxin, which is a marker of non-specific lymphoid IgG secretion commonly used in immunology, has never been tested in CSF. Is the intrathecal synthesis influenced by the schedule of immunizations (by infectious agents or vaccine) related to the time of MS onset? In other words, is the chance of acquiring non-specific intrathecal synthesis modified by the time of immunization, whether it occurs before, around, or after the clinical onset of MS? Once activated, B-cells have matured to $\mathrm{PC}$ in secondary lymphoid organs in response to an antigenic challenge, and long-lived PC migrate to bone marrow where they definitely home in nests providing a metabolic support. In this way, CNS may only recruit some PC during their short time frame 
of blood circulation succeeding B-cell differentiation. As a consequence, it may be that more than being an immune scar from early infection or immunization (6), non-specific intrathecal synthesis recapitulates and freezes the major antigenic challenges endured by the patient since MS onset. Elevated AI should be more common in protracted chronic CNS infections than in acute infection: an $\mathrm{MRH}$ reaction was described in a chronic case of neuro-borreliosis whereas no AI was elevated (except against borrelia) in an acute infection (58). There have been three case reports of MS with an initially normal AI that increased on a subsequent control lumbar puncture: two cases corresponded to current immunization against rubella and one case to a fresh VZV infection (72). Monitoring the differential intrathecal response to vaccines received early in life (i.e., anti-tetanus toxin) and those given later (i.e., hepatitis $A / B$, human papillomavirus) may help to demonstrate this hypothesis.

\section{REASSESSING THE PARADOX OF LOW INTRATHECAL ANTI-EBV REACTION}

Besides opening the debate on the significance of EBV infection in $\mathrm{MS}(73,74)$, we now focus on intrathecal reaction against EBV (52). In a cohort of 24 CIS/MS patients selected for known intrathecal synthesis against $\mathrm{EBV}, F_{\mathrm{S}}$ was in the same range against EBV (median $0.65 \%$, range $0.01-4.78 \%$ ) as against MRZ (52). One outlier patient had an $F_{\mathrm{s}}$ anti-EBV of $18.2 \%$. When considering IgG against EBV, absolute levels are higher in most of MS patients than controls, both in serum and in CSF (75), although high CSF levels are more likely linked to blood-barrier dysfunction than to intrathecal synthesis (76). However, anti-EBV intrathecal values have shown that an unexpectedly small proportion of patients have intrathecal synthesis (52, 56, 77-79): for example, anti-VCA AI was elevated in 2/80 MS patients and anti-EBNA1 in 5/80, but there was no difference with control groups (77). In a study focusing on anti-EBNA1, intrathecal synthesis occurred in 5/76 MS and in 13/75 controls (78). In CIS patients (optic neuritis) sampled within 1 month after clinical onset, only $2 / 36(6 \%)$ had an elevated AI ( $\left.F_{\mathrm{s}} 0.12-0.41 \%\right)$, whereas all were seropositive (52). In another study including 43 childhood and 50 adult onset MS, intrathecal synthesis occurred against measles, rubella, and VZV in $30-60 \%$ of pediatric and adult patients, whereas synthesis against anti-EBNA1 and anti-VCA occurred respectively only in 21 and $14 \%$ in the pediatric group and 8 and $2 \%$ in the adult group (80). Moreover, AI against EBV is sometimes twofold lower than AI against each MRZ component (80) but similar elsewhere (52). A difference in seroprevalence can be ruled out. Measles and rubella seroprevalence resulting either from natural infection or vaccination exceed $90 \%$ in most populations and vaccination campaigns started decades before (15), varicella seroprevalence exceeds 90\% in all European populations and EBV seroprevalence is virtually complete in MS patients.

The lower than expected intrathecal response against EBV is not consistent with the strong correlation linking high serum anti-EBV levels and MS activity. In the light of this finding, such an extreme discrepancy can be interpreted as a strong clue for EBV infection preceding MS clinical onset (52). Similarly, one can suppose that EBV infection triggers a strong humoral response during which the homing of EBV-specific long-lived PC mostly precedes the onset of intrathecal inflammation and the formation of brain TLO. As a consequence, EBV-specific PC have less likelihood of being recruited by brain TLO, and therefore intrathecal AI against EBV remains paradoxically low. A different interpretation may involve a driving role of EBV-infected B-cells and PC (81), potentially modifying their ability to secrete antibodies against EBV antigens. The peculiar relation of EBV with MS pathology is reinforced by the demonstration of a high intrathecal EBV-specific CD8+ cytotoxic activity only early in MS patients, without recruitment of CD8+ cells against different targets (CMV-specific CD8+ cells) (82). Longitudinal studies of patients' CSF for MRZ and EBV may help to assess whether the paradox of the low anti-EBV reaction is attributable to the schedule of primary infection or to a key pathophysiological point.

\section{DERIVING PRACTICAL CONSEQUENCES FOR MS CARE. CAN WE INFER CNS TLO FROM A SIMPLE CSF ANALYSIS?}

A growing set of evidence points to a central role of TLO in the formation and maintenance of intrathecal synthesis. Moreover, cortical TLO may play a key role in progressive MS $(1,42,83,84)$. Yet even though TLO structures may reach a considerable diameter (up to $1.1 \mathrm{~mm}$ ), which may make them a target for future neuroimaging, most of them are barely detectable (about 50-100 cells) even after a thorough pathological examination (85). Unless uncovering a specific marker, TLO confirmation by conventional MRI seems a flimsy hope and biological techniques may be more advisable. Is there a CSF biological marker of TLO presence or persistence?

Tertiary lymphoid organs are able to support local clonal proliferation of B- and T-cells and provide survival niches for PC. T-cell clonal response has been demonstrated to be both "private" to brain regions and "public" since it is shared throughout the brain in all MS patients, and TCR clonotypes are strictly private to patients (46). Clonotype analysis of B-cell repertoire in multiple anatomical brain areas, including meningeal aggregates and CSF, showed a large overlap between local repertoires. As a consequence, analysis of the CSF clonotype repertoire gives a representative sample of the meningeal repertoire $(86,87)$. The CSF B-cell family germline repertoire is strongly biased to $\mathrm{VH} 4$ and $\mathrm{VH} 3$ (88) and private clonotypes are expanded from single ancestors $(89,90)$. Somatic hypermutations in CDR within RGYW/WRCY motifs of IgG (47), which are targeted by the activation-induced cytidinedeaminase (AICD) specifically expressed in lymphoid organs, suggest that most of these lineage cells have undergone a local germinal center reaction (91). All these indirect arguments strongly suggest the presence of TLO but necessitate high-level biological tests unavailable in routine practice. In fact, intrathecally produced IgG - elevated index, specific $F_{\mathrm{s}}$, OCB - is one of the major terminal products of TLO production and seems to be a valuable indirect hallmark of CNS TLO. To date, no therapy has reversed acquired intrathecal synthesis in MS. A series of 76 patients treated by natalizumab offers one exception: $16 \%$ were controlled negative for OCB after treatment, and the proportion of patients with an intrathecal synthesized fraction in the normal range increased from 20 to $45 \%$ (44). As a consequence, we propose that intrathecal IgG secretion could be used to monitor future TLO-targeted therapies. 
We therefore hypothesize that intrathecal immune suppression should negate intrathecal IgG secretion by clearing CNS TLO (1). Clinical trials using intrathecal drugs offer a real hope to cure progressive MS. However, these trials were designed to use intrathecal rituximab. A pitfall of this treatment may be the resistance of CD20+ B-cells nested in TLO as observed in rheumatoid arthritis, and the persistence of local IgG secretion as observed in serum (1, 92). In fact, after intravenous + intrathecal rituximab treatment, a complete B-cell depletion is obtained in serum but depletion is still incomplete in CSF at 3 months: $-85 \%$ for B-cells, $-82 \%$ for T-cell (93). Results for IgG secretion and clinical/radiological data are not yet available. Although incomplete, these results suggest that intrathecal rituximab is a first step, but that it may not be sufficient alone to eradicate CNS TLO.

\section{CONCLUSION}

Although typical of MS, the non-specific intrathecal reaction has long been a theoretical issue. We propose to consider this nonspecific reaction as a common physiological property of intrathecal inflammation, involving the general properties of TLO located in the CNS. We extend this concept to (non-MS) CNS autoimmune and infectious disorders associated with intrathecal synthesis. Moreover, we propose that the cortical lesions associated with TLO observed in MS are not specific for MS but for TLO. We therefore propose the concept of "TLO-pathy" to describe cortical lesions associated with the presence of TLO. The concept of nonspecific secretion deserves further study to clarify the influence of immunization schedule.

\section{ACKNOWLEDGMENTS}

We are indebted to Ray Cooke for English assistance.

\section{REFERENCES}

1. Bonnan M. Intrathecal immune reset in multiple sclerosis: exploring a new concept. Med Hypotheses (2013) 82:300-9. doi:10.1016/j.mehy.2013.12.015

2. Gredler V, Reindl M. B cells accumulate in the cerebrospinal fluid in inflammatory neurological diseases. J Cytol Histol (2012) S1(001):1-7. doi:10.1016/j. neulet.2010.10.036

3. Beyer NH, Lueking A, Kowald A, Frederiksen JL, Heegaard NH. Investigation of autoantibody profiles for cerebrospinal fluid biomarker discovery in patients with relapsing-remitting multiple sclerosis. J Neuroimmunol (2012) 242(1-2):26-32. doi:10.1016/j.jneuroim.2011.08.013

4. Libbey JE, McCoy LL, Fujinami RS. Molecular mimicry in multiple sclerosis. Int Rev Neurobiol (2007) 79:127-47. doi:10.1016/S0074-7742(07)79006-2

5. Kuenzle S, von Budingen HC, Meier M, Harrer MD, Urich E, Becher B, et al. Pathogen specificity and autoimmunity are distinct features of antigen-driven immune responses in neuroborreliosis. Infect Immun (2007) 75(8):3842-7. doi:10.1128/IAI.00260-07

6. Robinson-Agramonte M, Reiber H, Cabrera-Gomez JA, Galvizu R. Intrathecal polyspecific immune response to neurotropic viruses in multiple sclerosis: a comparative report from Cuban patients. Acta Neurol Scand (2007) 115(5):312-8. doi:10.1111/j.1600-0404.2006.00755.x

7. Magliozzi R, Howell OW, Reeves C, Roncaroli F, Nicholas R, Serafini B, et al. A gradient of neuronal loss and meningeal inflammation in multiple sclerosis. Ann Neurol (2010) 68(4):477-93. doi:10.1002/ana.22230

8. Reiber H, Ungefehr S, Jacobi C. The intrathecal, polyspecific and oligoclonal immune response in multiple sclerosis. Mult Scler (1998) 4(3):111-7. doi:10.1191/135245898678909448

9. Rostasy K, Reiber H, Pohl D, Lange P, Ohlenbusch A, Eiffert H, et al. Chlamydia pneumoniae in children with MS: frequency and quantity of intrathecal antibodies. Neurology (2003) 61(1):125-8. doi:10.1212/01.WNL.0000070782.27949.F7
10. Reiber H. Cerebrospinal fluid - physiology, analysis and interpretation of protein patterns for diagnosis of neurological diseases. Mult Scler (1998) 4(3):99-107. doi:10.1191/135245898678909439

11. Derfuss T, Gurkov R, Then Bergh F, Goebels N, Hartmann M, Barz C, et al. Intrathecal antibody production against Chlamydia pneumoniae in multiple sclerosis is part of a polyspecific immune response. Brain (2001) $\mathbf{1 2 4}(\mathrm{Pt}$ 7):1325-35. doi:10.1093/brain/124.7.1325

12. Franciotta D, Di Stefano AL, Jarius S, Zardini E, Tavazzi E, Ballerini C, et al. Cerebrospinal BAFF and Epstein-Barr virus-specific oligoclonal bands in multiple sclerosis and other inflammatory demyelinating neurological diseases. $J$ Neuroimmunol (2011) 230(1-2):160-3. doi:10.1016/j.jneuroim.2010.10.027

13. Owens GP, Burgoon MP, Devlin ME, Gilden DH. Extraction and purification of active IgG from SSPE and MS brain. J Virol Methods (1997) 68(2):119-25. doi:10.1016/S0166-0934(97)00118-3

14. Brettschneider J, Tumani H, Kiechle U, Muche R, Richards G, Lehmensiek V, et al. IgG antibodies against measles, rubella, and varicella zoster virus predict conversion to multiple sclerosis in clinically isolated syndrome. PLoS One (2009) 4(11):e7638. doi:10.1371/journal.pone.0007638

15. Brecht I, Weissbrich B, Braun J, Toyka KV, Weishaupt A, Buttmann M. Intrathecal, polyspecific antiviral immune response in oligoclonal band negative multiple sclerosis. PLoS One (2012) 7(7):e40431. doi:10.1371/journal.pone.0040431

16. Jarius S, Franciotta D, Bergamaschi R, Rauer S, Wandinger KP, Petereit HF, et al. Polyspecific, antiviral immune response distinguishes multiple sclerosis and neuromyelitis optica. J Neurol Neurosurg Psychiatry (2008) 79(10):1134-6. doi:10.1136/jnnp.2007.133330

17. Rosche B, Laurent S, Conradi S, Hofmann J, Ruprecht K, Harms L. Measles IgG antibody index correlates with T2 lesion load on MRI in patients with early multiple sclerosis. PLoS One (2012) 7(1):e28094. doi:10.1371/journal.pone.0028094

18. Ahlgren C, Oden A, Bergstrom T, Lycke J. Serum and CSF measles antibody levels increase over time in patients with multiple sclerosis or clinically isolated syndrome. J Neuroimmunol (2012) 247(1-2):70-4. doi:10.1016/j.jneuroim.2012. 03.014

19. Ahlgren C, Oden A, Haghighi S, Andersen O, Bergstrom T, Lycke J. The effect of live, attenuated measles vaccine and measles infection on measles antibody levels in serum and CSF of patients with multiple sclerosis or clinically isolated syndrome. J Neuroimmunol (2011) 235(1-2):98-103. doi:10.1016/j.jneuroim. 2011.04.002

20. Fainardi E, Castellazzi M, Tamborino C, Seraceni S, Tola MR, Granieri E, et al. Chlamydia pneumoniae-specific intrathecal oligoclonal antibody response is predominantly detected in a subset of multiple sclerosis patients with progressive forms. J Neurovirol (2009) 15(5-6):425-33. doi:10.3109/13550280903475580

21. Sandberg-Wollheim M, Vandvik B, Nadj C, Norrby E. The intrathecal immune response in the early stage of multiple sclerosis. J Neurol Sci (1987) 81(1):45-53. doi:10.1016/0022-510X(87)90182-1

22. Fainardi E, Castellazzi M, Casetta I, Cultrera R, Vaghi L, Granieri E, et al. Intrathecal production of Chlamydia pneumoniae-specific high-affinity antibodies is significantly associated to a subset of multiple sclerosis patients with progressive forms. J Neurol Sci (2004) 217(2):181-8. doi:10.1016/j.jns.2003.09. 012

23. Krametter D, Niederwieser G, Berghold A, Birnbaum G, Strasser-Fuchs S, Hartung HP, et al. Chlamydia pneumoniae in multiple sclerosis: humoral immune responses in serum and cerebrospinal fluid and correlation with disease activity marker. Mult Scler (2001) 7(1):13-8. doi:10.1191/135245801676514804

24. Yao SY, Stratton CW, Mitchell WM, Sriram S. CSF oligoclonal bands in MS include antibodies against Chlamydophila antigens. Neurology (2001) 56(9):1168-76. doi:10.1212/WNL.56.9.1168

25. Franciotta D, Zardini E, Bergamaschi R, Grimaldi LM, Andreoni L, Cosi V. Analysis of Chlamydia pneumoniae-specific oligoclonal bands in multiple sclerosis and other neurologic diseases. Acta Neurol Scand (2005) 112(4):238-41. doi:10.1111/j.1600-0404.2005.00407.x

26. Derfuss T, Hohlfeld R, Meinl E. Intrathecal antibody (IgG) production against human herpesvirus type 6 occurs in about $20 \%$ of multiple sclerosis patients and might be linked to a polyspecific B-cell response. J Neurol (2005) 252(8):968-71. doi:10.1007/s00415-005-0794-z

27. Virtanen JO, Pietilainen-Nicklen J, Uotila L, Farkkila M, Vaheri A, Koskiniemi M. Intrathecal human herpesvirus 6 antibodies in multiple sclerosis and other demyelinating diseases presenting as oligoclonal bands in cerebrospinal fluid. $J$ Neuroimmunol (2011) 237(1-2):93-7. doi:10.1016/j.jneuroim.2011.06.012 
28. Bednárová J, Stourac P, Adam P. Relevance of immunological variables in neuroborreliosis and multiple sclerosis. Acta Neurol Scand (2005) 112(2):97-102. doi:10.1111/j.1600-0404.2005.00418.x

29. Felgenhauer K, Schadlich HJ, Nekic M, Ackermann R. Cerebrospinal fluid virus antibodies. A diagnostic indicator for multiple sclerosis? J Neurol Sci (1985) 71(2-3):291-9. doi:10.1016/0022-510X(85)90067-X

30. Woyciechowska JL, Dambrozia J, Leinikki P, Shekarchi C, Wallen W, Sever J, et al. Viral antibodies in twins with multiple sclerosis. Neurology (1985) 35(8):1176-80. doi:10.1212/WNL.35.8.1176

31. Thompson JA, Bray PF, Glasgow LA. Multiple sclerosis and elevation of cerebrospinal fluid vaccinia virus antibody. Neurology (1975) 25(1):94-6. doi:10. 1212/WNL.25.1.94

32. Chu VT, Berek C. The establishment of the plasma cell survival niche in the bone marrow. Immunol Rev (2013) 251(1):177-88. doi:10.1111/imr.12011

33. Eriksson K, Quiding-Jarbrink M, Osek J, Moller A, Bjork S, Holmgren J, et al Specific-antibody-secreting cells in the rectums and genital tracts of nonhuman primates following vaccination. Infect Immun (1998) 66(12):5889-96.

34. Manz RA, Hauser AE, Hiepe F, Radbruch A. Maintenance of serum antibody levels. Annu Rev Immunol (2005) 23:367-86. doi:10.1146/annurev.immunol.23. 021704.115723

35. Cao Y, Gordic M, Kobold S, Lajmi N, Meyer S, Bartels K, et al. An optimized assay for the enumeration of antigen-specific memory B cells in different compartments of the human body. J Immunol Methods (2010) 358(1-2):56-65. doi:10.1016/j.jim.2010.03.009

36. Withers DR, Fiorini C, Fischer RT, Ettinger R, Lipsky PE, Grammer AC. T celldependent survival of CD20+ and CD20- plasma cells in human secondary lymphoid tissue. Blood (2007) 109(11):4856-64. doi:10.1182/blood-2006-08043414

37. Thaunat O, Patey N, Caligiuri G, Gautreau C, Mamani-Matsuda M, Mekki Y, et al. Chronic rejection triggers the development of an aggressive intragraft immune response through recapitulation of lymphoid organogenesis. Jimmunol (2010) 185(1):717-28. doi:10.4049/jimmunol.0903589

38. Rosengren S, Wei N, Kalunian KC, Zvaifler NJ, Kavanaugh A, Boyle DL. Elevated autoantibody content in rheumatoid arthritis synovia with lymphoid aggregates and the effect of rituximab. Arthritis Res Ther (2008) 10(5):R105. doi:10.1186/ar2497

39. Winter O, Dame C, Jundt F, Hiepe F. Pathogenic long-lived plasma cells and their survival niches in autoimmunity, malignancy, and allergy. J Immunol (2012) 189(11):5105-11. doi:10.4049/jimmunol.1202317

40. Krumbholz M, Theil D, Cepok S, Hemmer B, Kivisakk P, Ransohoff RM, et al. Chemokines in multiple sclerosis: CXCL12 and CXCL13 up-regulation is differentially linked to CNS immune cell recruitment. Brain (2006) 129(Pt 1):200-11. doi:10.1093/brain/awh680

41. Corcione A, Casazza S, Ferretti E, Giunti D, Zappia E, Pistorio A, et al. Recapitulation of B cell differentiation in the central nervous system of patients with multiple sclerosis. Proc Natl Acad Sci U S A (2004) 101(30):11064-9. doi:10.1073/pnas.0402455101

42. Magliozzi R, Howell O, Vora A, Serafini B, Nicholas R, Puopolo M, et al. Meningeal B-cell follicles in secondary progressive multiple sclerosis associate with early onset of disease and severe cortical pathology. Brain (2007) $130(\mathrm{Pt}$ 4):1089-104. doi:10.1093/brain/awm038

43. Prineas JW, Wright RG. Macrophages, lymphocytes, and plasma cells in the perivascular compartment in chronic multiple sclerosis. Lab Invest (1978) 38(4):409-21.

44. Harrer A, Tumani H, Niendorf S, Lauda F, Geis C, Weishaupt A, et al. Cerebrospinal fluid parameters of B cell-related activity in patients with active disease during natalizumab therapy. Mult Scler (2013) 19(9):1209-12. doi: $10.1177 / 1352458512463483$

45. Butinx M, Moreels M, Vandenabeele F, Lambrichts I, Raus J, Steels P, et al. Cytokine-induced cell death in human oligodendroglial cell lines: I. Synergistic effects of IFNg and TNFa on apoptosis. J Neurosci Res (2004) 76:834-45. doi:10.1002/jnr.20118

46. Junker A, Ivanidze J, Malotka J, Eiglmeier I, Lassmann H, Wekerle H, et al. Multiple sclerosis: T-cell receptor expression in distinct brain regions. Brain (2007) 130(Pt 11):2789-99. doi:10.1093/brain/awm214

47. Harp C, Lee J, Lambracht-Washington D, Cameron E, Olsen G, Frohman E, et al. Cerebrospinal fluid B cells from multiple sclerosis patients are subject to normal germinal center selection. J Neuroimmunol (2007) 183(1-2):189-99. doi:10.1016/j.jneuroim.2006.10.020
48. Zhang Y, Da R-R, Guo W, Ren H-M, Hilgenberg LG, Sobel RA, et al. Axon reactive $\mathrm{B}$ cells clonally expanded in the cerebrospinal fluid of patients with multiple sclerosis. J Clin Immunol (2005) 25(3):254-64. doi:10.1007/s10875005-4083-5

49. Jacobi C, Lange P, Reiber H. Quantitation of intrathecal antibodies in cerebrospinal fluid of subacute sclerosing panencephalitis, herpes simplex encephalitis and multiple sclerosis: discrimination between microorganism-driven and polyspecific immune response. J Neuroimmunol (2007) 187(1-2):139-46. doi: 10.1016/j.jneuroim.2007.04.002

50. Conrad AJ, Chiang EY, Andeen LE, Avolio C, Walker SM, Baumhefner RW, et al. Quantitation of intrathecal measles virus IgG antibody synthesis rate: subacute sclerosing panencephalitis and multiple sclerosis. J Neuroimmunol (1994) 54(1-2):99-108. doi:10.1016/0165-5728(94)90236-4

51. Otto C, Hofmann J, Finke C, Zimmermann M, Ruprecht K. The fraction of varicella zoster virus-specific antibodies among all intrathecally-produced antibodies discriminates between patients with varicella zoster virus reactivation and multiple sclerosis. Fluids Barriers CNS (2014) 11(1):3. doi:10.1186/20458118-11-3

52. Otto C, Oltmann A, Stein A, Frenzel K, Schroeter J, Habbel P, et al. Intrathecal EBV antibodies are part of the polyspecific immune response in multiple sclerosis. Neurology (2011) 76(15):1316-21. doi:10.1212/WNL.0b013e318215286d

53. Graef IT, Henze T, Reiber H. [Polyspecific immune reaction in the central nervous system in autoimmune diseases with CNS involvement]. Z Arztl Fortbild (Jena) (1994) 88(7-8):587-91.

54. Vrethem M, Ernerudh J, Lindstrom F, Skogh T. Immunoglobulins within the central nervous system in primary Sjogren's syndrome. J Neurol Sci (1990) 100(1-2):186-92. doi:10.1016/0022-510X(90)90032-I

55. Jarius S, Eichhorn P, Jacobi C, Wildemann B, Wick M, Voltz R. The intrathecal, polyspecific antiviral immune response: specific for MS or a general marker of CNS autoimmunity? J Neurol Sci (2009) 280(1-2):98-100. doi:10.1016/j.jns. 2008.08.002

56. Nociti V, Frisullo G, Marti A, Luigetti M, Iorio R, Patanella AK, et al. EpsteinBarr virus antibodies in serum and cerebrospinal fluid from multiple sclerosis, chronic inflammatory demyelinating polyradiculoneuropathy and amyotrophic lateral sclerosis. J Neuroimmunol (2010) 225(1-2):149-52. doi:10.1016/ j.jneuroim.2010.04.007

57. Puccioni-Sohler M, Kitze B, Felgenhauer K, Graef IT, Lange P, Novis S, et al. The value of CSF analysis for the differential diagnosis of HTLV-I associated myelopathy and multiple sclerosis. Arq Neuropsiquiatr (1995) 53(4):760-5. doi:10.1590/S0004-282X1995000500008

58. Reiber H, Lange P. Quantification of virus-specific antibodies in cerebrospinal fluid and serum: sensitive and specific detection of antibody synthesis in brain. Clin Chem (1991) 37(7):1153-60.

59. Puel J, Gayet C, Averous S, Brochier B. Synthèse intrathécale des anticorps viraux au cours des encéphalits virales. Med Mal Infect (1982) 10:616-9.

60. Felgenhauer K, Luer W, Poser S. Chronic HIV encephalitis. J Neuroimmunol (1988) 20(2-3):141-4. doi:10.1016/0165-5728(88)90145-2

61. Felgenhauer K, Reiber $H$. The diagnostic significance of antibody specificity indices in multiple sclerosis and herpes virus induced diseases of the nervous system. Clin Investig (1992) 70(1):28-37. doi:10.1007/BF00422934

62. Vandvik B, Skoldenberg B, Forsgren M, Stiernstedt G, Jeansson S, Norrby E. Long-term persistence of intrathecal virus-specific antibody responses after herpes simplex virus encephalitis. J Neurol (1985) 231(6):307-12. doi:10.1007/ BF00313707

63. Riikonen R, Meurman O. Long-term persistence of intrathecal viral antibody responses in postinfectious diseases of the central nervous system and in Rett syndrome. Neuropediatrics (1989) 20(4):215-9. doi:10.1055/s-2008-1071296

64. Vandvik B, Vartdal F, Norrby E. Herpes simplex virus encephalitis: intrathecal synthesis of oligoclonal virus-specific IgG, IgA and IgM antibodies. J Neurol (1982) 228(1):25-38. doi:10.1007/BF00313407

65. Vandvik B, Nilsen RE, Vartdal F, Norrby E. Mumps meningitis: specific and nonspecific antibody responses in the central nervous system. Acta Neurol Scand (1982) 65(5):468-87. doi:10.1111/j.1600-0404.1982.tb03104.x

66. Kaiser R. Variable CSF findings in early and late Lyme neuroborreliosis: a followup study in 47 patients. J Neurol (1994) 242(1):26-36. doi:10.1007/BF00920571

67. Chattopadhyay S, Ito M, Cooper JD, Brooks AI, Curran TM, Powers JM, et al. An autoantibody inhibitory to glutamic acid decarboxylase in the neurodegenerative disorder Batten disease. Hum Mol Genet (2002) 11(12):1421-31. doi:10.1093/hmg/11.12.1421 
68. Korenke GC, Reiber H, Hunneman DH, Hanefeld F. Intrathecal IgA synthesis in X-linked cerebral adrenoleukodystrophy. J Child Neurol (1997) 12(5):314-20. doi:10.1177/088307389701200505

69. Lowhagen GB, Andersson M, Blomstrand C, Roupe G. Central nervous system involvement in early syphilis. Part 1 . Intrathecal immunoglobulin production. Acta Derm Venereol (1983) 63(5):409-17.

70. Lisak RP, Benjamins JA, Nedelkoska L, Barger JL, Ragheb S, Fan B, et al. Secretory products of multiple sclerosis B cells are cytotoxic to oligodendroglia in vitro. J Neuroimmunol (2012) 246(1-2):85-95. doi:10.1016/j.jneuroim.2012. 02.015

71. Steelman AJ, Li J. Poly(I:C) promotes TNFalpha/TNFR1-dependent oligodendrocyte death in mixed glial cultures. J Neuroinflammation (2011) 8:89. doi:10.1186/1742-2094-8-89

72. Reiber H, Teut M, Pohl D, Rostasy KM, Hanefeld F. Paediatric and adult multiple sclerosis: age-related differences and time course of the neuroimmunological response in cerebrospinal fluid. Mult Scler (2009) 15(12):1466-80. doi: $10.1177 / 1352458509348418$

73. Willis SN, Stadelmann C, Rodig SJ, Caron T, Gattenloehner S, Mallozzi SS, et al. Epstein-Barr virus infection is not a characteristic feature of multiple sclerosis brain. Brain (2009) 132(Pt 12):3318-28. doi:10.1093/brain/awp200

74. Aloisi F, Serafini B, Magliozzi R, Howell OW, Reynolds R. Detection of Epstein-Barr virus and B-cell follicles in the multiple sclerosis brain: what you find depends on how and where you look. Brain (2010) 133(Pt 12):e157. doi:10.1093/brain/awq223

75. Bray PF, Luka J, Bray PF, Culp KW, Schlight JP. Antibodies against EpsteinBarr nuclear antigen (EBNA) in multiple sclerosis CSF, and two pentapeptide sequence identities between EBNA and myelin basic protein. Neurology (1992) 42(9):1798-804. doi:10.1212/WNL.42.9.1798

76. Jafari N, van Nierop GP, Verjans GM, Osterhaus AD, Middeldorp JM, Hintzen RQ. No evidence for intrathecal IgG synthesis to Epstein Barr virus nuclear antigen-1 in multiple sclerosis. J Clin Virol (2010) 49(1):26-31. doi:10.1016/j. jcv.2010.06.007

77. Castellazzi M, Tamborino C, Cani A, Negri E, Baldi E, Seraceni S, et al. EpsteinBarr virus-specific antibody response in cerebrospinal fluid and serum of patients with multiple sclerosis. Mult Scler (2010) 16(7):883-7. doi:10.1177/ 1352458510368051

78. Villegas E, Santiago O, Carrillo JA, Sorlozano A, Guerrero M, Fernandez O, et al. Low intrathecal immune response of anti-EBNA-1 antibodies and EBV DNA from multiple sclerosis patients. Diagn Microbiol Infect Dis (2011) 70(1):85-90. doi:10.1016/j.diagmicrobio.2010.11.013

79. Sargsyan SA, Shearer AJ, Ritchie AM, Burgoon MP, Anderson S, Hemmer B, et al. Absence of Epstein-Barr virus in the brain and CSF of patients with multiple sclerosis. Neurology (2010) 74(14):1127-35. doi:10.1212/WNL. 0b013e3181d865a1

80. Pohl D, Rostasy K, Jacobi C, Lange P, Nau R, Krone B, et al. Intrathecal antibody production against Epstein-Barr and other neurotropic viruses in pediatric and adult onset multiple sclerosis. J Neurol (2010) 257(2):212-6. doi:10.1007/s00415-009-5296-y

81. Magliozzi R, Serafini B, Rosicarelli B, Chiappetta G, Veroni C, Reynolds R, et al B-cell enrichment and Epstein-Barr virus infection in inflammatory cortical lesions in secondary progressive multiple sclerosis. J Neuropathol Exp Neurol (2013) 72(1):29-41. doi:10.1097/NEN.0b013e31827bfc62

82. Jaquiery E, Jilek S, Schluep M, Meylan P, Lysandropoulos A, Pantaleo G, et al. Intrathecal immune responses to EBV in early MS. Eur J Immunol (2010) 40(3):878-87. doi:10.1002/eji.200939761
83. Lucchinetti CF, Popescu BF, Bunyan RF, Moll NM, Roemer SF, Lassmann H, et al. Inflammatory cortical demyelination in early multiple sclerosis. $N$ Engl J Med (2011) 365(23):2188-97. doi:10.1056/NEJMoa1100648

84. von Budingen HC, Bar-Or A, Zamvil SS. B cells in multiple sclerosis: connecting the dots. Curr Opin Immunol (2011) 23(6):713-20. doi:10.1016/j.coi.2011.09. 003

85. Kuerten S, Schickel A, Kerkloh C, Recks MS, Addicks K, Ruddle NH, et al. Tertiary lymphoid organ development coincides with determinant spreading of the myelin-specific T cell response. Acta Neuropathol (2012) 124(6):861-73. doi:10.1007/s00401-012-1023-3

86. Lovato L, Willis SN, Rodig SJ, Caron T, Almendinger SE, Howell OW, et al. Related B cell clones populate the meninges and parenchyma of patients with multiple sclerosis. Brain (2011) 134(Pt 2):534-41. doi:10.1093/brain/awq350

87. Skorstad G, Vandvik B, Vartdal F, Holmoy T. MS and clinically isolated syndromes: shared specificity but diverging clonal patterns of virus-specific IgG antibodies produced in vivo and by CSF B cells in vitro. Eur J Neurol (2009) 16(10):1124-9. doi:10.1111/j.1468-1331.2009.02657.x

88. Owens GP, Winges KM, Ritchie AM, Edwards S, Burgoon MP, Lehnhoff L, et al. VH4 gene segments dominate the intrathecal humoral immune response in multiple sclerosis. J Immunol (2007) 179(9):6343-51.

89. Colombo M, Dono M, Gazzola P, Roncella S, Valetto A, Chiorazzi N, et al. Accumulation of clonally related B lymphocytes in the cerebrospinal fluid of multiple sclerosis patients. J Immunol (2000) 164(5):2782-9.

90. von Budingen HC, Kuo TC, Sirota M, van Belle CJ, Apeltsin L, Glanville J, et al. $B$ cell exchange across the blood-brain barrier in multiple sclerosis. J Clin Invest (2012) 122(12):4533-43. doi:10.1172/JCI63842

91. Meinl E, Krumbholz M, Hohlfeld R. B lineage cells in the inflammatory central nervous system environment: migration, maintenance, local antibody production, and therapeutic modulation. Ann Neurol (2006) 59(6):880-92. doi:10.1002/ana.20890

92. Edwards JC, Szczepanski L, Szechinski J, Filipowicz-Sosnowska A, Emery P, Close DR, et al. Efficacy of B-cell-targeted therapy with rituximab in patients with rheumatoid arthritis. N Engl J Med (2004) 350(25):2572-81. doi:10.1056/ NEJMoa032534

93. Bielekova B, Herman ML. Method of treating multiple sclerosis by intrathecal depletion of B cells and biomarkers to select patients with progressive multiple sclerosis. Google Patents (2013). Patent No. WO2013049362.

Conflict of Interest Statement: The author declares that the research was conducted in the absence of any commercial or financial relationships that could be construed as a potential conflict of interest.

Received: 28 December 2013; accepted: 26 February 2014; published online: 11 March 2014

Citation: Bonnan M (2014) Does disease-irrelevant intrathecal synthesis in multiple sclerosis make sense in the light of tertiary lymphoid organs? Front. Neurol. 5:27. doi: 10.3389/fneur.2014.00027

This article was submitted to Multiple Sclerosis and Neuroimmunology, a section of the journal Frontiers in Neurology.

Copyright (C) 2014 Bonnan. This is an open-access article distributed under the terms of the Creative Commons Attribution License (CC BY). The use, distribution or reproduction in other forums is permitted, provided the original author(s) or licensor are credited and that the original publication in this journal is cited, in accordance with accepted academic practice. No use, distribution or reproduction is permitted which does not comply with these terms. 